How to cite this published article:

Nechyporchuk, O.; Kolman, K.; Oriola, M.; Persson, M.; Holmberg, K.; Bordes, R. Accelerated ageing of cotton canvas as a model for further consolidation practices, Journal of Cultural Heritage, 28 (2017), pg. 183-187. doi.org/10.1016/j.culher.2017.05.010

\title{
Accelerated ageing of cotton canvas as a model for further consolidation
} practices

Oleksandr Nechyporchuk ${ }^{\text {a, }, *}$, Krzysztof Kolman ${ }^{a}$, Marta Oriola ${ }^{b}$, Michael Persson ${ }^{\text {a,c }}$, Krister Holmberg ${ }^{\text {a }}$, Romain Bordes ${ }^{\mathrm{a}, * *}$

${ }^{a}$ Department of Chemistry and Chemical Engineering, Applied Surface Chemistry, Chalmers University of Technology, SE-412 96 Gothenburg, Sweden

${ }^{\mathrm{b}}$ Conservation Section, Faculty of Fine Arts, University of Barcelona, C/Pau Gargallo, 4, 08028 Barcelona, Spain.

${ }^{c}$ AkzoNobel Pulp and Performance Chemicals AB, SE-445 34 Bohus, Sweden

${ }^{1}$ Present address: Swerea IVF, SE-431 22 Mölndal, Sweden.

*o.nechyporchuk@gmail.com

**bordes@chalmers.se

\section{Abstract}

In order to assess the effectiveness of various practices for canvas consolidation, model substrates are needed. In this work, a method of rapid ageing of cotton canvas is described. The method consists of treatment of the canvas with a mixture of hydrogen peroxide and sulfuric acid at $40{ }^{\circ} \mathrm{C}$ during 72 hours to mimic to some extent the natural processes of oxidation and acidcatalysed hydrolysis of cellulose. Two protocols for canvas degradation were developed, which reduce the degree of polymerization of cellulose from $c a$. 6250 to $c a .1350$ and 450 . The reduction of the mechanical properties and the increase of the negative charge were also quantified. These samples were compared with a canvas degraded using a state-of-the-art method that takes up to 20 days. The results show that the developed method can provide a rapid procedure for preparing small samples for testing various consolidation strategies by conservators.

Keywords: Cotton canvas, artificial ageing, accelerated degradation, oxidation, acid-catalysed hydrolysis, canvas conservation. 


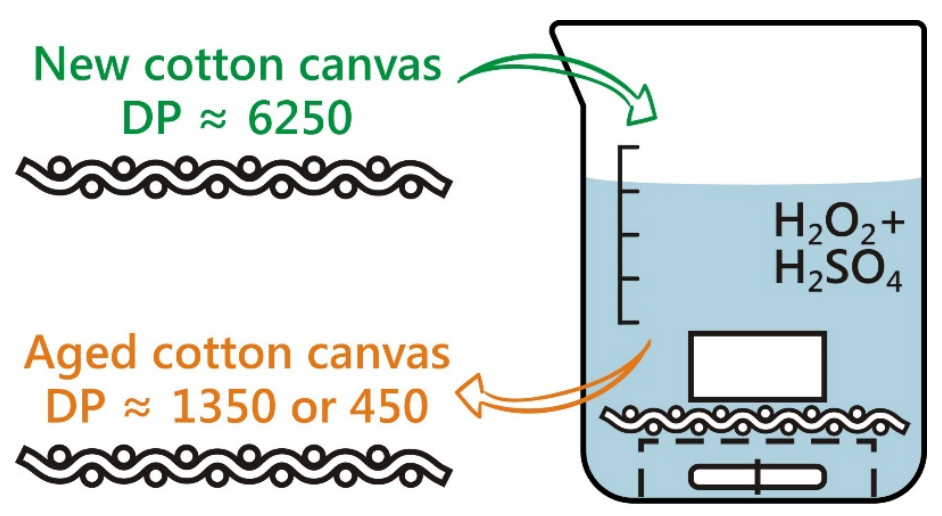

\section{Introduction}

An important problem with easel painting conservation is to arrest the degradation process occurring with its organic components, one of which is cellulosic canvas, and to consolidate the degraded material. The degradation process results in deterioration of the canvas strength and ultimately affects the integrity of the paint layer. When the canvas is subjected to tension on a stretcher, the degradation is influenced by various parameters: humidity and temperature fluctuations, UV irradiation, chemistry of different painting layers, air pollution, etc. [1-3]. Undoubtedly, it is hard to determine the exact influence of all these parameters (separately or together) on the canvas properties in the long-term perspective. However, it is generally known that the two dominant processes involved in cellulose degradation are oxidation and acid-catalysed hydrolysis [4-7], as shown in Error! No s'ha trobat l'origen de la referència..

a

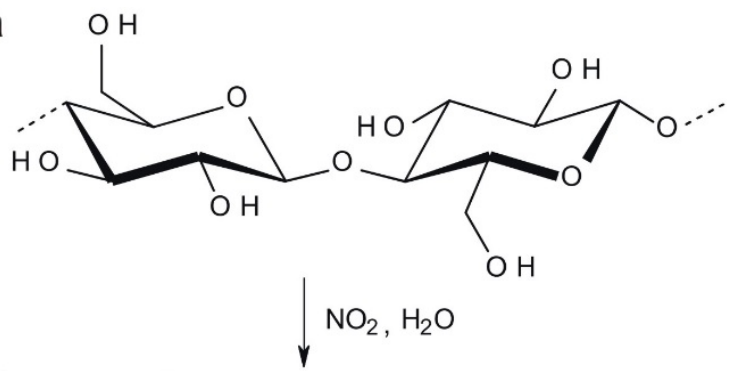

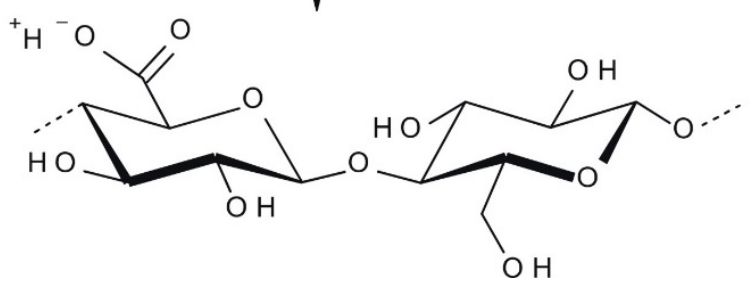

b
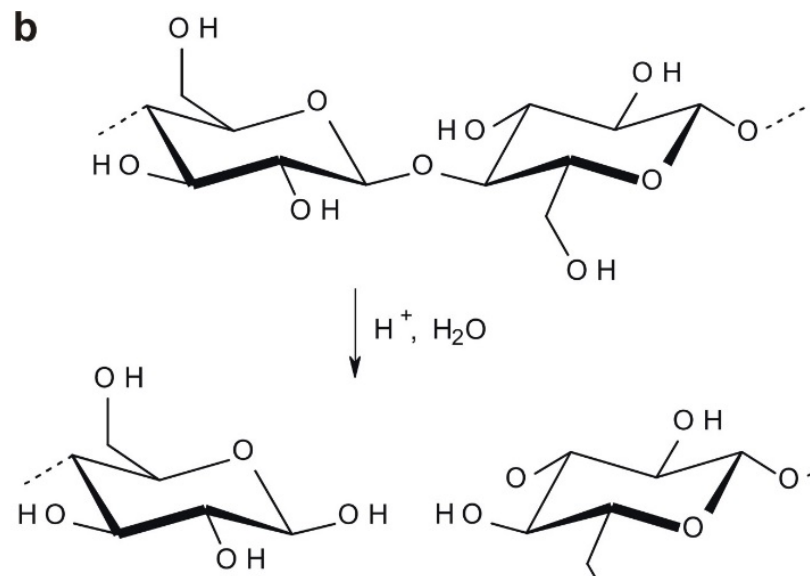<smiles>CO[C@H]1O[C@H](CO)[C@@H](O)[C@H](O)[C@H]1O</smiles>

Fig. 1. Degradation mechanisms of cellulose chains: (a) oxidation of hydroxyl groups yielding carboxylic acids (in this case nitrogen dioxide, a well-known atmospheric pollutant, acts as oxidant) and (b) acid-catalysed hydrolysis leading to cleavage of the polymeric chains.

Cellulose oxidation originates, for instance, from acidic gases, such as nitrogen dioxide (see Error! No s'ha trobat l'origen de la referència.a). Additionally, photo-oxidation and thermal oxidation occur that involve light absorption by certain substances, e.g., pigments, varnish or lignin, 
which create free radicals that initiate the oxidation process [6,7]. As a result, hydroxyl groups of cellulose chains are converted to carboxyl groups that have an acidic character [8].

The presence of acid catalyses the hydrolysis reaction that leads to scission of cellulose chains, transforming acetals to hemiacetals, see Error! No s'ha trobat l'origen de la referència.b). The cellulose chains are packed together forming nanofibrils that in turn are arranged to compose a cell wall of a single microscopic fibre [9]. The acid-catalyzed hydrolysis leads to a drastic decrease of the degree of polymerisation (DP), i.e., reduction of the length of the polymeric chains, which can be correlated to a reduction of the mechanical strength of the fibres [2]. For instance, for cotton the DP varies in the range of 8,000-14,000 depending on the treatment of the raw material [10]. During the degradation process, the DP is drastically decreased. It has been reported that a cotton painting canvas in satisfactory condition has a DP of $c a$. 1000, whereas a canvas with a DP of $<600$ is referred to as "very fragile", i.e., a painting with a canvas with such a low DP will have a high risk of being torn when handled [2]. The correlation between canvas degradation and its mechanical properties has been presented in a number of papers [11-13].

Various conservation practices are available for consolidation of degraded canvases [14-17]. Therefore, model substrates are needed by conservators in order to assess the effectiveness of different practices and some previous works have focused on accelerated ageing of cellulosic canvases [5,18-20]. It is known that cellulose can be degraded by various treatments, e.g., thermal, hydrolytic, photolytic, photochemical and enzymatic [11]. Hackney and Hedley [5] used light exposure for accelerated aging tests of linen canvas. Seves et al. [18] studied the accelerated thermal ageing of linen canvas. Carr et al. [19] used sulphuric acid treatments of linen canvas. Poggi et al. [20] reported a method of canvas ageing by soaking in sulfuric acid followed by thermal degradation. These methods offer possibilities to artificially degrade the canvas; however, they are all time consuming. For instance, the method of Carr et al. was carried out during 500 hours and the one of Poggi et al. for up to 300 hours.

In this work, a method of accelerated ageing of cotton canvas, which takes only 72 hours and which uses a mixture of hydrogen peroxide and sulfuric acid, is described. We focus on cotton since it represents the pure natural form of cellulose, compared to other natural fibers that contain lignin. Cellulose is the main component responsible for fiber strength and its degradation directly influences the reduction of the mechanical properties of the canvas. Therefore, cotton was used in this study. Another reason to choose cotton is the lack of methodologies for this type of canvas material. Cotton is widely employed as canvas material in contemporary art due to its intrinsic properties (white colour) and more favourable price compared to linen, which has been most commonly used due to its superior mechanical properties [21,22]. 


\section{Research aim}

The aim of this work is to synthesize a material that resembles the naturally aged painting canvas (subjected to usual storage conditions of paintings with respect to humidity, temperature and UV level) in terms of: (i) mechanical properties, (ii) DP, (iii) charge density (a measure of electric charge per unit volume), and (iv) chemistry. These data are difficult to find for naturally aged canvases, since the treatment and the handling history are usually unknown, leading to a broad spectrum of properties, not necessarily attributed to the degradation process of cotton. Therefore, in scope of this study, we target the other methodology of artificial ageing, reported by Poggi et al. [20], as a benchmark. This rapid degradation is aimed as a method to produce a model canvas that can be used for evaluation of the efficiency of various consolidation practices.

\section{Material and methods}

\subsection{Materials}

The cotton canvas with a basis weight of $417 \pm 3 \mathrm{~g} / \mathrm{m}^{2}$ and a plain weave was purchased from Barna Art (Barcelona, Spain). Hydrogen peroxide solution (35 wt \%) was purchased from Fisher Scientific GTF AB, Sweden. Sulfuric acid (95-97 wt\%) was purchased from Merck Chemicals and Life Science $\mathrm{AB}$, Sweden.

\subsection{Canvas preparation}

The canvas was washed prior to the measurements (DP, charge density, tensile testing, etc.) in order to remove residues of grease (e.g., tallow or mineral oil), commonly used in fabric weaving processes $[23,24]$, as well as possible sizing agents, both of which impart hydrophobicity to cellulose. The canvas $\left(\mathrm{ca} .1 \mathrm{~m}^{2}\right)$ was washed in a domestic washing machine at $60^{\circ} \mathrm{C}$ for $c a .40 \mathrm{~min}$ without any detergent and then kept in water in a $1 \mathrm{~L}$ double-jacket reactor at $85{ }^{\circ} \mathrm{C}$ with mechanical stirring. The washing was not performed prior to the accelerated ageing, which itself was very efficient for removal of the hydrophobic impurities.

\subsection{Accelerated ageing}

\subsubsection{Moderately degraded (MD) and highly degraded (HD) canvases}

Two models of aged canvas were developed by accelerated degradation. The method consists of treatment of $70 \times 80 \mathrm{~mm}$ new cotton canvas specimens $(1.78 \mathrm{~g})$ in a mixture of $200 \mathrm{~mL}$ of hydrogen peroxide $\left(\mathrm{H}_{2} \mathrm{O}_{2}\right)$ solution $(35 \mathrm{wt} \%)$ and either $10 \mathrm{~mL}$ or $1 \mathrm{~mL}$ of sulfuric acid $\left(\mathrm{H}_{2} \mathrm{SO}_{4}\right)$, resulting in models of highly degraded (HD) and moderately degraded (MD) canvas, respectively. The treatment was performed during 72 hours at $40{ }^{\circ} \mathrm{C}$ with mild magnetic stirring in the setup shown in Error! No s'ha trobat l'origen de la referència.. The magnetic bar was placed in a beaker and covered with a pierced polystyrene cup in order to avoid contact between the bar and the canvas, 
located above. The canvas was pressed with a polytetrafluoroethylene brick to avoid floating. After the ageing reaction, the canvas was thoroughly washed with deionized water until the conductivity of the effluent was $<5 \mu \mathrm{S} / \mathrm{cm}$ and was then dried under biaxial tension to prevent shrinkage.

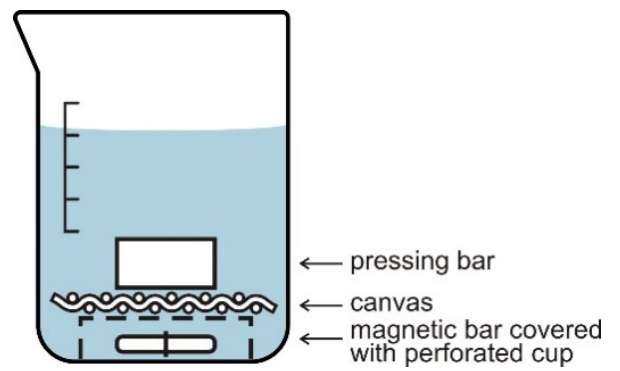

Fig. 2. Schematic representation of the setup for accelerated ageing of the canvas in a mixture of hydrogen peroxide and sulfuric acid.

\subsubsection{State-of-the-art degraded (SAD) canvases}

The above method was compared with a state-of-the-art degradation (SAD) method using sulfuric acid and thermal degradation, reported by Poggi et al. [20]. The method was performed with some minor deviations as follows. First, $c a .460 \mathrm{~g}$ of cotton canvas was immersed in tap water at $40{ }^{\circ} \mathrm{C} 3$ times for periods of $2 \mathrm{~h}, 24 \mathrm{~h}$ and $2 \mathrm{~h}$. The water was not kept warm; thus, it gradually cooled down to room temperature. Then, the canvas was air dried and put into $15 \mathrm{~L}$ of $0.001 \mathrm{M}$ $\mathrm{H}_{2} \mathrm{SO}_{4}$ aqueous solution for $4 \mathrm{~h}$. Wet samples were then placed between polyester films with a thickness of $15 \mu \mathrm{m}$ (Melinex) and transferred into the manual mechanical press (tightly pressed) overnight. The samples were afterwards placed on polyester nonwoven sheets with a thickness of $19 \mu \mathrm{m}$ (Reemay) to air dry. The canvas was aged at $90^{\circ} \mathrm{C}$ and $65 \%$ relative humidity (RH) in a climate chamber (type VC 0018, Vötsch Industrietechnik GmbH, Germany) for 18 days.

\subsection{Degree of polymerization (DP)}

The DP of cotton canvas was estimated based on the intrinsic viscosity values ( $\left.\eta_{\text {int }}\right)$ of cellulose dissolved in $0.5 \mathrm{M}$ copper (II)-ethylenediamine, as determined according to ISO 5351 [25]. The canvas was separated to threads to facilitate the dissolution. The viscometric average degree of polymerization $\left(D P_{\mathrm{v}}\right)$ was determined based on the Mark-Houwink-Sakurada equation with the parameters proposed by Evans and Wallis [26]:

$$
D P_{\mathrm{v}}^{0.85}=1.1 \eta_{\text {int. }}
$$

\subsection{Charge density}

The charge density of the canvases was measured using the particle charge detector PCD-02 (Mütek Analytic GmbH, Germany). Canvas samples of $c a .0 .1 \mathrm{~g}$ were separated to threads, dispersed in $10 \mathrm{~mL}$ of ultrapure water (Milli-Q) and titrated with an aqueous solution of the cationic polymer, polydiallyldimethylammonium chloride (polyDADMAC), having a charge density of 

$220 \mu \mathrm{eq} / \mathrm{L}$. The titration was performed using a DL21 titrator (Mettler Toledo, USA) with an equilibrium of $0.5 \mathrm{mV} / \mathrm{s}$, time increment of $20 \mathrm{~s}$ and a potential change of $8 \mathrm{mV}$. The canvas charge density was calculated as follows:

$$
q_{\mathrm{c}}=\frac{q_{\mathrm{t}} \times V_{\mathrm{t}}}{m_{\mathrm{c}}}
$$

where $q_{\mathrm{c}}$ is the charge density of the canvas $(\mu \mathrm{eq} / \mathrm{g}) ; q_{\mathrm{t}}$ is the charge density of the titrant (polyDADMAC, $\mu \mathrm{eq} / \mathrm{L}$ ); $V_{\mathrm{t}}$ is the volume of added titrant $(\mathrm{L})$ and $m_{\mathrm{c}}$ is the oven-dry mass of the canvas $(\mathrm{g})$.

\subsection{Tensile testing}

Mechanical properties of the canvas samples were determined using tensile testing according to the ASTM D5034 - 09 method [27] with minor variations. An Instron 5565A (Norwood, MA, USA) instrument equipped with a $100 \mathrm{~N}$ or a $5000 \mathrm{~N}$ load cell (depending on the canvas strength) and pneumatic clamps with 5 bar pressure capacity was used for the measurements. Rectangular specimens with a length of $70 \mathrm{~mm}$ and a width of $10 \mathrm{~mm}$, cut parallel to the warp direction along the threads, were used. The specimens were conditioned for $12 \mathrm{~h}$ at $60 \% \mathrm{RH}$ and $23{ }^{\circ} \mathrm{C}$ before the measurements. Sandpaper was attached to the clamps prior to the testing to avoid canvas slippage and consequent overestimation of the sample elongation. Testing was performed at an extension rate of $300 \mathrm{~mm} / \mathrm{min}$ and a gauge length of $20 \mathrm{~mm}$. The data presented for each sample represents a mean of seven measurements. The data processing was performed using Bluehill software. The terms related to the force and deformation properties were used as specified in ASTM D4848 98(2012) [28].

\subsection{Scanning electron microscopy (SEM)}

The morphology of canvases before and after ageing was studied using a Leo Ultra 55 field emission gun SEM (Carl Zeiss SMT GmbH, Germany). The samples were mounted onto stubs and sputtered with a gold layer of $c a .10 \mathrm{~nm}$ using Sputter Coater S150B (Edwards, UK). The SEM was operated at an acceleration voltage of $3 \mathrm{kV}$.

\section{Results and discussion}

Preliminary tests on soaking the canvas in water revealed a pronounced hydrophobic nature of the purchased cotton canvas. Therefore, it was important to wash the canvas (as specified in the Materials and Methods section) especially before the charge density measurements and the viscometric DP determination. Without preliminary washing, the canvas did not completely solubilize in the copper(II)-ethylenediamine solution used for DP determination, which introduced systematic errors in the measurements. 
The increase of ionic charge (via carboxyl groups) on the fibre surface and the depolymerisation of cellulose chains occur during the process of canvas degradation as a result of cellulose oxidation and acid-catalysed hydrolysis, respectively. Error! No s'ha trobat l'origen de la referència. shows changes of the charge density and the DP of the samples as a result of the ageing treatments. The negative charge of the canvas increases progressively (see Error! No s'ha trobat l'origen de la referència.a and Table 1) from $0.7 \mu \mathrm{eq} / \mathrm{g}$ for the original canvas to $5.5 \mu \mathrm{eq} / \mathrm{g}$ and $13.7 \mu \mathrm{eq} / \mathrm{g}$ after treatment with increasingly higher concentration of sulfuric acid, resulting in MD and HD canvases. The oxidation is believed to occur due to the presence of hydrogen peroxide and peroxymonosulfuric acid, with the latter formed in situ by reaction of hydrogen peroxide and sulfuric acid.
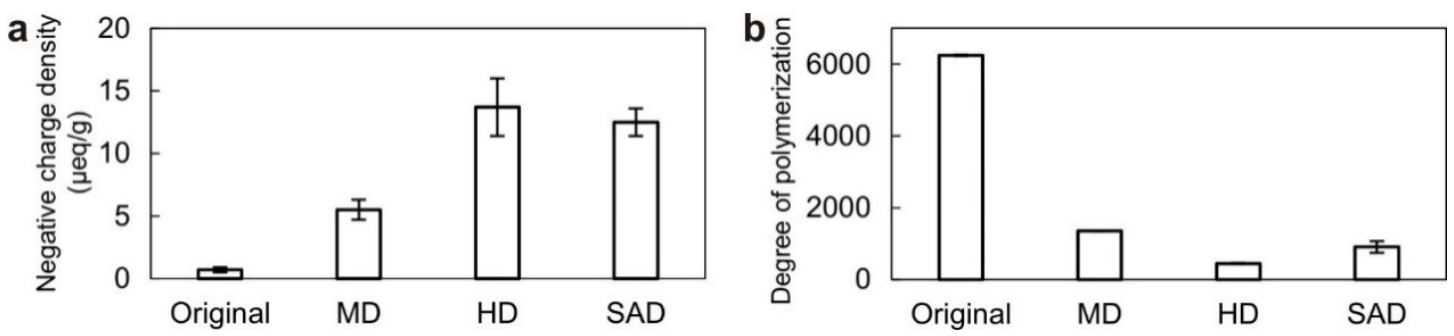

Fig. 3. Negative charge density (a) and degree of polymerization (b) of original, moderately degraded (MD), highly degraded (HD) and state-of-the-art degraded (SAD) cotton canvas.

Table 1. Properties of the original and the degraded canvases

\begin{tabular}{lcccc}
\hline Canvas sample & Original & $\begin{array}{c}\text { Moderately } \\
\text { degraded (MD) }\end{array}$ & $\begin{array}{c}\text { Highly degraded } \\
\text { (HD) }\end{array}$ & $\begin{array}{c}\text { State-of-the-art } \\
\text { degraded (SAD) }\end{array}$ \\
\hline Degree of polymerization & $6242 \pm 19$ & $1353 \pm 5$ & $451 \pm 7$ & $907 \pm 163$ \\
Breaking force $(\mathrm{N})$ & $176 \pm 8$ & $128 \pm 6$ & $42 \pm 4$ & $70 \pm 13$ \\
Elongation at break (\%) & $52 \pm 1$ & $47 \pm 2$ & $35 \pm 1$ & $43 \pm 2$ \\
Negative charge density $(\mu \mathrm{eq} / \mathrm{g})$ & $0.7 \pm 0.2$ & $5.5 \pm 0.8$ & $13.7 \pm 2.3$ & $12.5 \pm 1.1$ \\
\hline
\end{tabular}

The ageing also results in a drastic change of the DP, which drops from ca. 6250 to ca.1350 and 450 for MD and HD canvases, respectively. Based on these DP values and the correlation of the DP values with the condition of the canvas, presented in the Introduction section, we label these samples MD and HD. Regarding the SAD canvas, it has quite similar charge density as the HD canvas (12.5 vs. $13.7 \mu \mathrm{eq} / \mathrm{g}$, respectively), whereas the DP of the SAD canvas (907) is in between the values of the MD and the HD samples. Overall, the results from the proposed methods to prepare MD and HD canvases are comparable with those of the SAD canvas.

The reduction of the DP strongly affects the mechanical properties of the canvas, as shown in Error! No s'ha trobat l'origen de la referència.. The elongation-force curves measured in warp direction illustrate the decrease of the breaking force for the degraded cotton canvases, which is 
however not as drastic as the decrease of the DP. The breaking force is reduced from $176 \mathrm{~N}$ for the 216 original canvas to $128 \mathrm{~N}$ and $42 \mathrm{~N}$ for the MD and the HD canvases, respectively. As a result of 217 ageing, the canvases break at lower elongation, the values being reduced from $52 \%$ for the original 218 to $47 \%$ and $35 \%$ for the MD and the HD canvas, respectively. In other words, the canvases become 219 more brittle.. The mechanical properties of the SAD canvas lie between the values for the MD and 220 the HD samples (70 N and 43\% for breaking force and elongation at break, respectively). It is also 221 noteworthy that the standard deviation is smaller compared to that of SAD sample, which illustrates 222 the robustness of the degradation method. We have also tested a sample of aged canvas produced in 223 the same way as used for the HD canvas, but replacing hydrogen peroxide with water. The breaking 224 force for that sample was $65 \mathrm{~N}$, which is higher than that of the HD canvas, $42 \mathrm{~N}$. Thus, proving the better efficiency of the system containing both hydrogen peroxide and sulfuric acid in the 226 formulation.

a

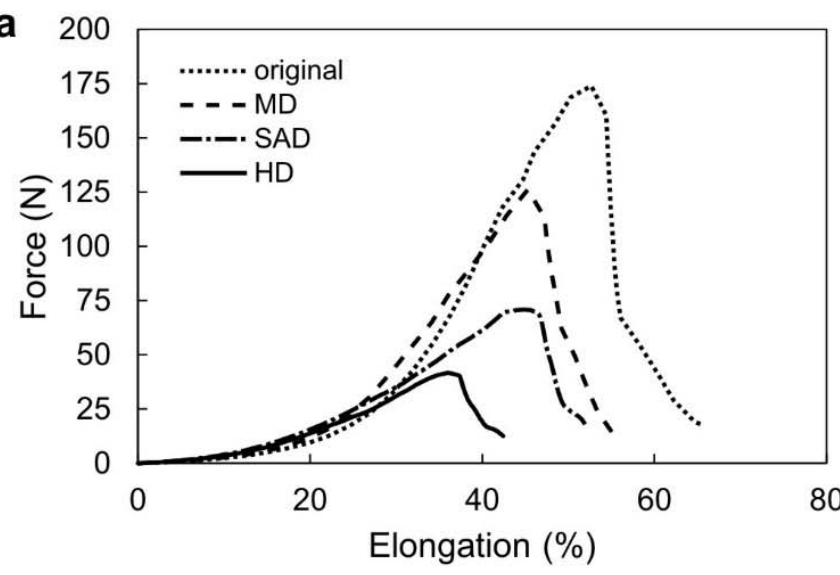

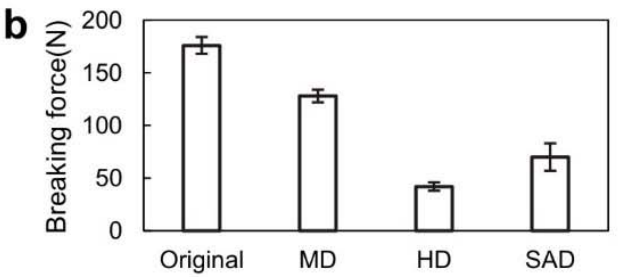

c

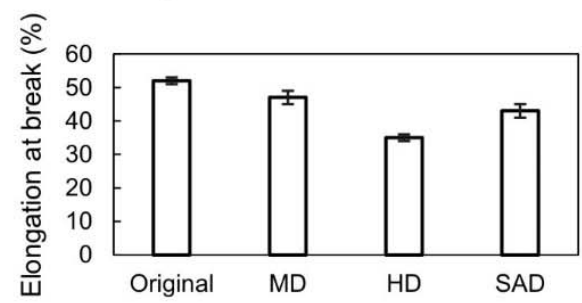

Fig. 4. Mechanical properties of original, highly degraded (HD), moderately degraded (MD) and state-of-the-art degraded (SAD) cotton canvases.

Despite the severe degradation reactions imposed on the cotton canvases, Error! No s'ha trobat

233 l'origen de la referència. shows that the HD sample has similar visual appearance as that of the 234 original canvas. The magnified image in Error! No s'ha trobat l'origen de la referència.b only reveals that the surface of the microscopic fibres becomes more rough (wrinkled), compared to the one in Error! No s'ha trobat l'origen de la referència.a. At the same time, there are some cracks present in both aged and non-aged samples. This suggests that the morphology of the woven canvas is overall preserved and that the accelerated aged canvas can serve as a model for further examination of the effectiveness of various consolidation treatments. 

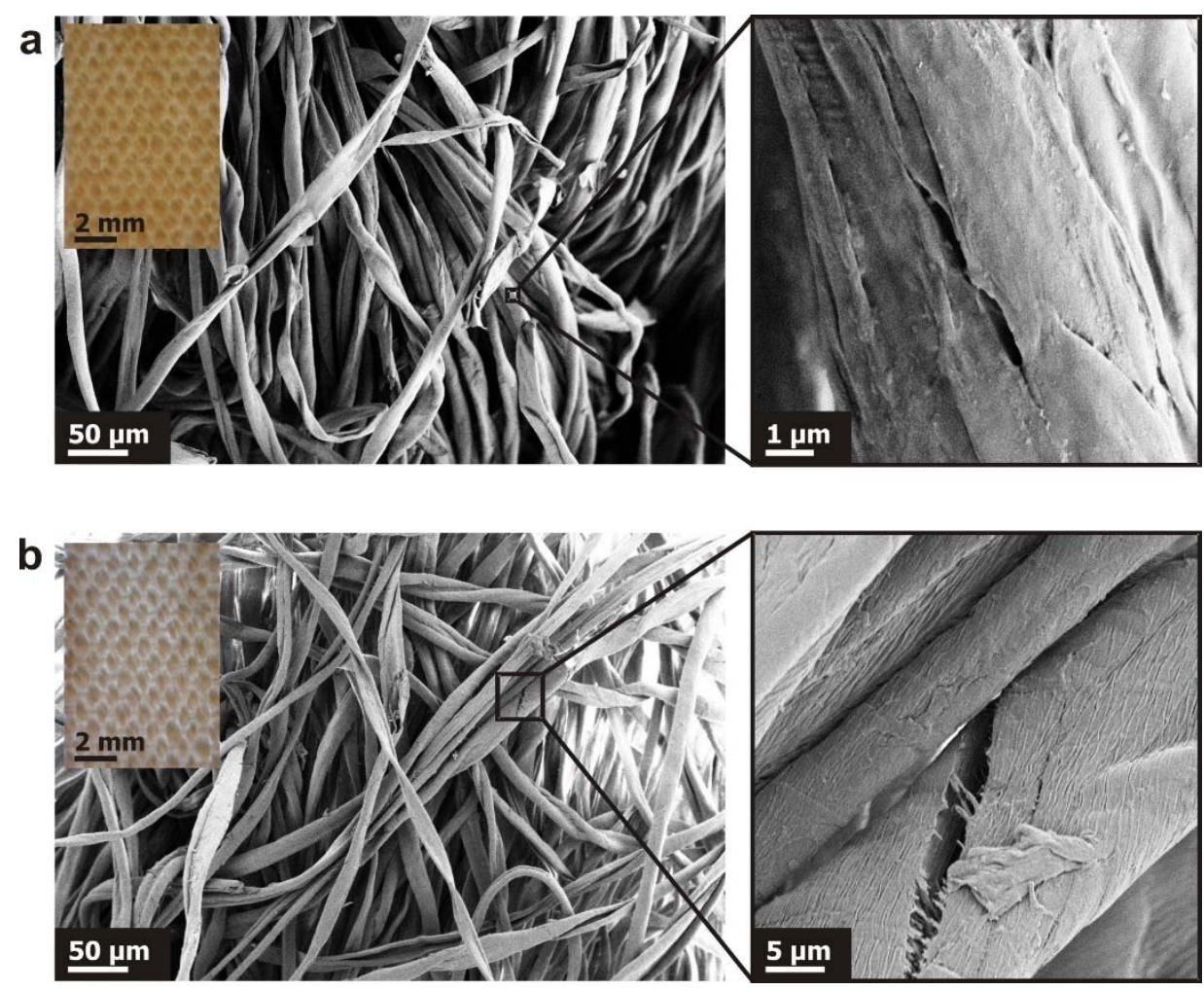

Fig. 5. SEM images of the original (a) and highly degraded (b) cotton canvases with optical microscopy images as insets (left top).

\section{Conclusions}

The developed methods for accelerated ageing of cotton canvas using a combination of hydrogen peroxide and sulfuric acid provide a rapid methodology to obtain small specimens of two model materials that can be referred to canvases in satisfactory and in bad condition (MD and HD samples, respectively). While strips of the HD canvas cut in warp direction (1 cm width) can be broken by hand, the MD canvas of the same dimension cannot. These samples can be used to assess the potential of various canvas consolidation practices.

\section{Acknowledgements}

This work has been performed within the frame of NANORESTART (NANOmaterials for the RESToration of works of ART) project funded by Horizon 2020 European Union Framework Program for Research and Innovation (Grant Agreement No. 646063). The authors gratefully acknowledge helpful discussions with Prof. Matija Strlič and Hend Mahgoub from University College London, UK, and with Prof. Irena Kralj Cigić from the University of Ljubljana, Slovenia.

\section{References}

[1] G. Hedley, Relative humidity and the stress/strain response of canvas paintings: uniaxial measurements of naturally aged samples, Studies in Conservation. 33 (1988) 133-148. doi:10.1179/sic.1988.33.3.133. 
[2] M. Oriola, A. Možir, P. Garside, G. Campo, A. Nualart-Torroja, I. Civil, M. Odlyha, M. Cassar, M. Strlič, Looking beneath Dalí's paint: non-destructive canvas analysis, Analytical Methods. 6 (2014) 86-96. doi:10.1039/C3AY41094C.

[3] R. Hendrickx, G. Desmarais, M. Weder, E.S.B. Ferreira, D. Derome, Moisture uptake and permeability of canvas paintings and their components, Journal of Cultural Heritage. 19 (2016) 445-453. doi:10.1016/j.culher.2015.12.008.

[4] A. Ekamstam, The behaviour of cellulose in mineral acid solutions. Kinetic study of the decomposition of cellulose in acid solution, Berichte Der Deutschen Chemischen Gesellschaft. 69 (1936) 553-559.

[5] S.J. Hackney, G.A. Hedley, The deterioration of linen canvas: accelerated aging tests to investigate the modes of deterioration and to assess retarding treatments, Studies in Conservation. 27 (1982) 151-153. doi:10.1179/sic.1982.27.Supplement-1.151.

[6] N. Ryder, Acidity in canvas painting supports: Deacidification of two 20th century paintings, The Conservator. 10 (1986) 31-36. doi:10.1080/01410096.1986.9995015.

[7] P. Baglioni, D. Chelazzi, R. Giorgi, G. Poggi, Colloid and materials science for the conservation of cultural heritage: cleaning, consolidation, and deacidification, Langmuir. 29 (2013) 5110-5122.

[8] M. Seery, Paper conservation, Education in Chemistry. (2013). http://www.rsc.org/images/EiC0213-paper-conservation-chemistry_tcm18-227485.pdf.

[9] O. Nechyporchuk, M.N. Belgacem, J. Bras, Production of cellulose nanofibrils: A review of recent advances, Industrial Crops and Products. 93 (2016) 2-25. doi:10.1016/j.indcrop.2016.02.016.

[10] V.K. Varshney, S. Naithani, Chemical Functionalization of Cellulose Derived from Nonconventional Sources, in: S. Kalia, B.S. Kaith, I. Kaur (Eds.), Cellulose Fibers: Bio- and Nano-Polymer Composites, Springer Berlin Heidelberg, 2011: pp. 43-60. http://link.springer.com/chapter/10.1007/978-3-642-17370-7_2 (accessed June 11, 2013).

[11] G. Testa, A. Sardella, E. Rossi, C. Bozzi, A. Seves, The kinetics of cellulose fiber degradation and correlation with some tensile properties, Acta Polym. 45 (1994) 47-49. doi:10.1002/actp.1994.010450109.

[12] C.R.T. Young, R.D. Hibberd, Biaxial tensile testing of paintings on canvas, Studies in Conservation. 44 (1999) 129-141. doi:10.1179/sic.1999.44.2.129.

[13] C.R.T. Young, R.D. Hibberd, The role of canvas attachments in the strain distribution and degradation of easel paintings, Studies in Conservation. 45 (2000) 212-220. doi:10.1179/sic.2000.45.Supplement-1.212.

[14] P. Ackroyd, A. Phenix, C. Villers, Not lining in the twenty-first century: Attitudes to the structural conservation of canvas paintings, The Conservator. 26 (2002) 14-23. doi:10.1080/01410096.2002.9995172.

[15] C. Villers, Post minimal intervention, The Conservator. 28 (2004) 3-10. doi:10.1080/01410096.2004.9995197.

[16] C. Young, S. Jardine, Fabrics for the twenty-first century: As artist canvas and for the structural reinforcement of easel paintings on canvas, Studies in Conservation. 57 (2012) 237253. doi:10.1179/2047058412Y.0000000007.

[17] K. Kolman, O. Nechyporchuk, M. Persson, K. Holmberg, R. Bordes, Preparation of silica/polyelectrolyte complexes for textile strengthening applied to painting canvas restoration, Colloids and Surfaces A: Physicochemical and Engineering Aspects. (2017). doi:10.1016/j.colsurfa.2017.04.051.

[18] A.M. Seves, S. Sora, G. Scicolone, G. Testa, A.M. Bonfatti, E. Rossi, A. Seves, Effect of thermal accelerated ageing on the properties of model canvas paintings, Journal of Cultural Heritage. 1 (2000) 315-322. doi:10.1016/S1296-2074(00)01078-5.

[19] D.J. Carr, C.R.T. Young, A. Phenix, R.D. Hibberd, Development of a Physical Model of a Typical Nineteenth-Century English Canvas Painting, Studies in Conservation. 48 (2003) 145154. doi:10.1179/sic.2003.48.3.145. 
[20] G. Poggi, N. Toccafondi, L.N. Melita, J.C. Knowles, L. Bozec, R. Giorgi, P. Baglioni, Calcium hydroxide nanoparticles for the conservation of cultural heritage: new formulations for the deacidification of cellulose-based artifacts, Applied Physics A. 114 (2014) 685-693. doi:10.1007/s00339-013-8172-7.

[21] M. Odlyha, G. Foster, S. Hackney, J. Townsend, Dynamic mechanical thermal analysis for the evaluation of deacidification treatment of painting canvases, Journal of Thermal Analysis and Calorimetry. 50 (1997) 191-202. doi:10.1007/BF01979561.

[22] C. Villers, Artist's canvases: A history, in: ICOM Committee for Conservation, 6th Triennial Meeting, Ottawa, 1981: pp. 1-12.

[23] E. Moss, The lubrication of cotton and other textiles, British Journal of Applied Physics. 2 (1951) 19. doi:10.1088/0508-3443/2/S1/307.

[24] O. Nechyporchuk, J. Yu, V.A. Nierstrasz, R. Bordes, Cellulose Nanofibril-Based Coatings of Woven Cotton Fabrics for Improved Inkjet Printing with a Potential in E-Textile Manufacturing, ACS Sustainable Chem. Eng. (2017). doi:10.1021/acssuschemeng.7b00200.

[25] ISO 5351:2010 Pulps - Determination of limiting viscosity number in cupri-ethylenediamine (CED) solution, (2010).

[26] R. Evans, A.F.A. Wallis, Comparison of cellulose molecular weights determined by high performance size exclusion chromatography and viscometry, in: Proceeding of the Fourth International Symposium on Wood and Pulping Chemistry, Paris, 1987: pp. 201-205.

[27] ASTM D5034 - 09 (2013) Standard Test Method for Breaking Strength and Elongation of Textile Fabrics (Grab Test), (2013).

[28] ASTM D4848 - 98(2012) Standard Terminology Related to Force, Deformation and Related Properties of Textiles, (2012). 